\title{
Experts, expertise, and health and physical education teaching: A scoping review of conceptualisations
}

Author 1: Dr Benjamin Williams (corresponding author)

ORCID iD: 0000-0002-8083-7876

Affiliation: School of Education and Professional Studies, Griffith University

Email: benjamin.williams@griffith.edu.au

Author 2: Dr Jessica Lee

Affiliation: School of Medicine, Griffith University

Email: jessica.lee@,griffith.edu.au

Disclosure Statement: We have no conflicts of interest to declare regarding this work. The work was unfunded and did not require ethical approval from an institutional review board.

Biographical Note. Dr Benjamin Williams is a Lecturer in Health and Physical Education in Griffith University's School of Education and Professional Studies, and is a member of the Griffith Institute for Educational Research. Dr Jessica Lee is a Senior Lecturer in Public Health in Griffith University's School of Medicine. 


\title{
Experts, expertise, and health and physical education teaching: A scoping review of conceptualisations
}

\begin{abstract}
Concerns about the supply of, and demand for, experts and expertise are prominent in research on outsourcing in health and physical education (HPE), and the state of the subject more broadly. Yet precisely what is meant by "expert" and "expertise" in this scholarship is not always clear or uncontested. In this research, we used a scoping review framework to examine how scholarly research has conceptualised experts and expertise in the context of HPE teaching. We enhanced this framework by analysing the ways these conceptualisations have, and have not, attended to the relationality, materiality, and performativity of either concept. Following searching and screening processes, 72 articles were included in the review. Eighteen articles provided definitions or detailed descriptions of what an expert or expertise was taken to be in the context of HPE teaching, four of which were commonly cited across the sample. Three ontologies of experts and/or expertise were evident within these definitions/descriptions: psychological, social, and network. These ontologies and the conceptualisations based upon them exhibited varying sensitivity to relationality, materiality, and performativity. To better register the complexities of HPE teaching in contemporary contexts, we encourage researchers to become more attuned to these dimensions of experts and expertise, and advocate a material-semiotic approach to doing so. Keywords: experts; expertise; physical education; material semiotics
\end{abstract}

\section{Introduction}

Over the past decade, outsourcing has been the focus of considerable attention among health and physical education (HPE) researchers. An ever-increasing number of articles have reported on the practice (see Sperka \& Enright, 2018), and two special issues have been 
devoted to exploring it and the privatisation processes of which it is a part (see Evans \& Davies, 2015; Macdonald, Johnson, \& Lingard, 2020). As researchers have answered calls for further study of its various iterations and consequences, the prevalence and perniciousness of outsourcing have been observed across an internationally diverse range of educational settings. Chief among the concerns raised in this scholarship are the ways outsourcing is redefining relations between teachers, students, and subject matter, and reconfiguring relations between education, commerce, philanthropy, health, sport, and government. This corpus has also illustrated how outsourcing has reproduced existing practices in HPE, such as the subject matter dominance of sports.

The topics of experts and expertise are deeply implicated in the HPE outsourcing literature. In a recent scoping review, Sperka and Enright (2018) observed that the most frequently reported justification for outsourcing has been to access external providers' expertise. These authors also noted the frequency with which outsourcing was justified on the grounds that external providers' work served as illustrations of expert practice and, thus, were useful sources of professional development. Such findings paint a picture of teachers that tend to lack the expertise required to teach HPE, and schools that generally lack the necessary experts in HPE teaching. This image of deficiency is not unique to the outsourcing literature. It has also been a recurring depiction in global surveys of the state of the subject (e.g., Hardman, Murphy, Routen, \& Tones, 2014). Yet precisely what is meant by “expert” and "expertise" in these portrayals is not always clear. In many respects, this ambiguity within HPE scholarship should not surprise. As Stigler and Miller (2018) note, despite years of effort, educational researchers, more broadly, "still lack a clear conception of what it means to be an expert teacher" (p. 431).

The purpose of this article is to investigate how researchers have conceptualised experts and expertise in the context of HPE teaching. In so doing, we problematise both 
concepts. This problematisation is premised on two contentions. First, we contend that talk about experts and expertise must be understood as socially and historically specific. The nature, meaning, and role of experts and expertise have varied across times, places and problems (Abbott, 1988), and have frequently been matters of contestation (Eyal, 2019).

Second, we contend that the ways HPE researchers talk about experts and expertise particularly the ways they understand, research, and represent these concepts - help shape the subject's potentialities and the boundaries of the profession(s) involved in their pursuit (see Thorburn \& Gray, this issue). As we explain below, both these contentions are grounded in our study's theoretical approach.

\section{Theoretical approach}

In this study, we adopted a material-semiotic approach. Material semiotics is a set of analytic tools and sensibilities that treats all entities "as a continuously generated effect of the webs of relations within which they are located," and assumes that "nothing has reality or form outside the enactment of those relations" (Law, 2009, p. 141). By adopting this approach, we sought to attune ourselves to three interrelated dimensions of experts and expertise in the context of HPE teaching. The first of these dimensions was the relationality of experts and expertise. Material semiotics "claims that entities give each other being: that they enact each other" (Law \& Mol, 2008, p. 58). Thus, a material-semiotic approach sensitised us to the range of interrelated entities that bring experts or expertise into being (and vice versa). Material semiotics also teaches that these collections of interrelated entities are materially diverse (Law \& Mol, 2008). Therefore, material semiotics drew our attention to the heterogeneous materiality of the webs of relations that bring experts and expertise into being. Finally, a concern with performativity - with how these semiotically relational and materially heterogeneous webs "assemble and together enact a set of practices that make a more or less precariousness reality" (Law, 2009, p. 151) - is central to material semiotics. Material 
semiotics, then, also helped us register the ways in which experts and expertise are performed into existence via these webs of relations and the social practices that carry them.

Material semioticians have used these sensibilities to formulate broad conceptualisations of both experts and expertise. Following this work, we conceptualised expertise as a web of relations between "objects, actors, techniques, devices, and institutional and spatial arrangements" (Eyal, 2013, p. 864) that produces "the capacity to carry out certain specialized tasks that are either impossible to carry out in its absence, or that are performed better, faster and with greater certainty of desired outcomes in its presence" (Eyal, 2019, p. 35). Furthermore, we understood expertise as "an ongoing accomplishment, rather than as the unquestioned mobilization of well-defined, pre-existing bodies of knowledge" (Cambrosio, Limoges, \& Hoffman, 1992, p. 349). Similarly, we conceptualised an expert as an entity typically, but not exclusively, a person - to which the superior performance of some specialised task is attributed via the web of materialised relations and social practices in which it is enmeshed (Cambrosio et al., 1992). Thus, we understood expert status as a provisional outcome of jurisdictional claims over a specialised task on the basis of that task's superior performance (Cambrosio et al., 1992; Eyal, 2013).

Material-semiotic approaches to experts and expertise have emerged in response to critiques of existing scholarship. For several decades, a large body of research has studied the origins and effects of the epistemic, social and political authority of experts and expertise (Eyal, 2019). At the heart of much of this work has an attempt to resolve a set of ongoing tensions regarding the problems of legitimacy and extension (Collins \& Evans, 2002). In this context, the problem of extension concerns the boundaries of participation (i.e., who or what should be involved in debates and decisions about matters of public concern) while the problem of legitimacy concerns the limits of trust (i.e., which experts, expert systems, or expertise to have confidence in, and which to question or challenge). As Landström and 
Whatmore (2014) show, research that has grappled with these problems has often been underpinned by the assumptions that experts and expertise always pose problems for democracy, and that expertise is an acquired, intellectual property of individual experts. Material semioticians argue that these assumptions have endured because researchers have not paid sufficient empirical and historical attention to the practices constitutive of experts and expertise, and the various objects, artefacts, relationships, institutions, and so on that are integral to these practices (e.g., Eyal, 2013). Advocates of material semiotics have also highlighted how material-semiotic sensibilities can help change inequitable approaches to the problems of legitimacy and extension that characterise much of life in contemporary democracies (e.g., Callon, Lascoumes, \& Barthe, 2009).

The contribution of material semiotics to our research was not confined to the task of theorising experts and expertise. It also provided us a means of interrogating scholarly texts. The production, circulation, and use of academic texts have long been a focus of material semioticians (e.g., Latour \& Woolgar, 1986). Within this tradition, academic texts have been identified as integral elements within the web of heterogeneous materials that compose natural and social scientific knowledge practices. As literary inscriptions, academic texts help give form to their authors, their readers, and the entities and events they depict. They do this formatting work through the narratives embedded in them, the tropes they draw on, and the political agendas they carry (Law, 2017). To attend to these tropes, in particular, highlights the important role of concepts in structuring "what we perceive, how we get around in the world, and how we relate to other people" (Lakoff \& Johnson, 1980, p. 3). From a materialsemiotic perspective, the concepts deployed in academic texts are devices that make certain entities and events academically thinkable, sensible, and articulatable. In this way, concepts both represent these entities or events, and bring them into being. Thus, concepts both shape, and are shaped, by the realities reported in scholarly texts. To this end, we used material- 
semiotic sensibilities to examine how academic texts contribute to the enactment of experts and expertise in the context of HPE teaching. We did so by investigating the various conceptualisations of these terms within the scholarly literature.

\section{Method}

To complete this investigation, we conducted a scoping review. A scoping review is "a form of knowledge synthesis that addresses an exploratory research question ... by systematically searching, selecting, and synthesizing existing knowledge" (Colquhoun et al., 2014, pp. 1293-1294). Scoping reviews have traditionally been used to map the nature and scope of existing research on a given topic, judge the feasibility of conducting a full systematic review, disseminate summaries of previous findings, and/or identify gaps in current knowledge (Levac, Colquhoun, \& O’Brien, 2010). However, it has also become increasingly common for scoping reviews to be used to identify, clarify, and examine key concepts in a body of literature (Munn et al., 2018) - the purpose for which we deployed the method. To this end, we followed the five-stage framework typical of scoping reviews: identify the research question, identify relevant sources, select included sources, extract and chart relevant data, and summarise and report findings (Arksey \& O’Malley, 2005). We did not complete the framework's optional consultation stage, an omission we address later.

Nevertheless, our use of scoping review methods also deviated from the process as it is conventionally prescribed and practiced. The primary way we deviated from this process was by challenging the ontological and epistemological foundations of traditional scoping review methods. Scoping reviews are designed to be descriptive rather than evaluative undertakings (Arksey \& O’Malley, 2005). The scoping reviewer's task is not to appraise the quality of the methods used, the data generated, or the conclusions drawn in each included source (Grant \& Booth, 2009). Instead, their job is to compile an inventory of faithfully extracted information and then describe the general themes, trends and patterns evident in the 
literature as a whole. In this way, traditional scoping review methods require the researcher to treat "each article as an objective piece of the knowledge puzzle" and uncritically accept "knowledge merely due to its status as knowledge" (Dalmer, 2020, p. 6). However, analysing scholarly texts from a material-semiotic perspective requires a different set of sensibilities. Therefore, in addition to creating the kind of bibliographic summary typical of a conventional scoping review, we actively interrogated the language researchers used to discuss experts and expertise in the context of HPE teaching, reading within and across the included sources to identify patterns and trends in the ways these concepts have been depicted and deployed. Conducting our study in such a manner was consistent with our concern to acknowledge the performativity of research practices, and the relationality, materiality, and performativity of experts and expertise. It was also consistent with the recent efforts of researchers like Dalmer (2020), who have sought to appropriate the scoping review as a critical knowledge synthesis tool.

Scoping reviews begin with the development of a broad, well-defined research question and a clearly articulated scope (Levac et al., 2010). Our review was guided by the question, "how has scholarly research conceptualised experts and expertise in the context of HPE teaching, and to what extent have these conceptualisations acknowledged the relationality, materiality, and performativity of either concept?" When answering this question, we restricted our scope to scholarship on HPE teaching in schooling contexts, and research on pre-service HPE teachers in teacher education settings. We did not explore the literature on coaches and instructors performing non-school-related tasks, nor research on how students acquire motor skills in HPE contexts. This restricted scope reflected our interest in the future of HPE teachers' work and its intersection with notions of experts and expertise.

We searched two databases to identify sources relevant to our review: Scopus and Web of Science Core Collection. These two databases index journals, books, and conference 
proceedings for all disciplines, including a wide range of well-known, peer-reviewed HPE journals, and therefore provided sufficient breadth for our review. In Scopus, we searched for sources with "expert*", "physical educat*", and "teach*" in the title, abstract, or key terms fields. In Web of Science Core Collection, we searched for the same terms in the topic field. We limited our results in both databases to the English language, but we did not set a timeframe, as we hoped to search the literature as far back as possible. We also handsearched the literature for relevant sources using reference harvesting, forward citation searching, and our knowledge of the research field. All the sources we identified via handsearching had to meet the same criteria used when searching the databases.

We did not use synonyms for expert or expertise in our search strategies (e.g., specialist, authority, knowledge, or skill), and we did not search for related terms (e.g., experienced teacher). Our reason for doing so was that, like Eyal (2019), our interest lay in the pragmatics of experts and expertise. In the sense we use the term here, pragmatics can be defined as "the study of language use in context" (Huang, 2017, p. 1). While our review was not a formal pragmatic analysis, it was motivated by the pragmatic impulse to examine how language (i.e., the terms expert and expertise) has been used in a particular context (i.e., scholarly literature about HPE teaching). By not searching for synonyms or related terms, we were able to focus specifically on how expert and expertise have been used in the HPE teaching literature and to consider who has used these terms, how they have used them, for what purpose, and with what consequences. From this perspective, the use of synonyms or related terms only interested us when an author explicitly associated, substituted, or conflated those terms with expert or expertise.

Our search, conducted in February 2020, yielded 728 records: 719 through our database searches and 9 via hand-searches. We then removed 145 duplicates and 502 records through a screening process conducted at the level of title and abstract. We assessed the 
eligibility of the remaining records by reading each source. During the screening and reading processes, we used the following inclusion criteria: the source addressed experts/expertise in the context of HPE teaching; the source contained at least one use of these terms in a way that made it possible to identify its referent; and, the source was an English language, peerreviewed journal article, book chapter, or scholarly monograph. Because our research question focused on conceptualisations, we included empirical studies, literature reviews, theoretical essays, and methodological pieces in the review.

\section{Findings}

Seventy-two sources were included in the review, all of which were journal articles. Fiftynine articles reported empirical studies. The 72 articles were published in 21 different journals, 11 of which had an explicit focus on HPE, physical activity or sport. The earliest article was published in 1989, and the most recent article was published in 2020. The articles fell into one of twelve categories according to its focus. The five most common foci were: the nature and development of teaching expertise $(n=25)$; outsourcing/external providers $(n=11)$; teaching models/approaches $(n=6)$; teachers' identities, work and career trajectories $(n=5)$; and the state of the subject/teaching profession $(n=3)$. An underlying premise of most of the sample was that experts and expertise, when properly conceived or recognised, were beneficial to the teaching of HPE, and that a lack of either was detrimental or less desirable.

Eighteen articles provided definitions or sufficiently detailed descriptions of what an expert or expertise is in the context of HPE teaching. These articles either presented established uses of the terms within the research or broader community, or reported observed properties that served as the basis of the definition (see Fetzer, 1991). Rocha and Clemente (2012) exemplified the former approach when they defined an expert as "a person who is very knowledgeable about or skillful in a particular area," expertise "as specialisation in a particular field or area where the subject possesses the mastery of skills or knowledge," and 
an expert teacher as one with "enormous expertise in a particular field" (p. 557). By contrast, Sharpe and Hawkins (1992) typified the latter approach when they defined the expert HPE teacher as exhibiting "mastery of the subject matter" (p. 69), "a consistent rhythm, a high velocity, a coherent yet flexible structure, and a fluent orchestration of elements" (p. 73). Only three articles raised the possibility of students being experts or as having expertise within the pedagogical encounter (Barker, Quennerstedt, \& Annerstedt, 2015; Díaz-Cueto, Hernández-Álvarez, \& Castejón, 2010; Enright, Kirk, \& Macdonald, 2020).

Four articles from the sample were frequently cited in the definitions provided in the rest of the sample. The first was Siedentop and Eldar (1989), who conceptualised teaching expertise as "highly specific to context and subject matter" (p. 257) such that the expert teacher "combines high levels of teaching skill ... with high levels of subject matter competence, both applied through experience to a particular context” (p. 257). The second commonly cited article was Dodds' (1994) conceptualisation of teaching expertise as “a global construct that refers to the ease with which teachers perform their work to maximise student learning" (p. 156), and expert teaching as the "masterful orchestration of the entire panoply of effective teaching behaviours, each used at the appropriate time and with the right students” (p. 161). In the third influential article, O’Sullivan and Doutis (1994) conceived of expert teachers "as virtuosos" who have a "sophisticated knowledge of their subject matter," and the ability to "demonstrate in their culturally relevant physical education programs and socially responsible teaching a knowledge of and sensitivity to the uniqueness of their learners and their cultural contexts" (p. 179). In the last frequently cited article, Ennis (1994) conceptualised curricular expertise as a teacher's ability "to select and convey content appropriate to the learner within a particular contextual setting and situation" (p. 164), and the expert teacher as one who makes "contextually appropriate decisions about students and the knowledge base with planning and teaching" (p. 175). 
Most articles in the sample did not provide clear definitions or descriptions of experts or expertise. More commonly, authors used the terms in tangential or colloquial ways. In these instances, expertise was used as a shorthand or synonym for HPE-related knowledge or skills, experience teaching HPE in schools, or relevant HPE teaching or coaching qualifications. Occasionally, the term expert was used to refer to a specialist HPE teacher, and it was frequently used with reference to external providers.

Three ontologies of experts and/or expertise were evident within the sample, the first of which was psychological. Within this ontology, the expert teacher was conceptualised as an individual person with a keen sensitivity and skilful responsiveness to relevant aspects of the pedagogical encounter. In the behavioural variant of this ontology, "the expert is under considerably larger, more highly differentiated response repertoire, and with stronger control from setting events relative to the subject matter as applied to a particular context" (Siedentop \& Eldar, 1989, p. 260). By contrast, in this ontology's cognitive variant, “experts have amassed a large quantity of knowledge and possess elaborate cognitive schemata for meaningful interpretation and effective decision-making that achieves performance" (Schempp, Manross, Tan, \& Fincher, 1998, p. 343). In both variants, expertise was presented as an attribute of the expert. Most conceptualisations within the sample were underpinned by a psychological ontology that foregrounded the behavioural, cognitive and/or affective characteristics of expert teachers or teaching expertise.

The second ontology was social. Only two articles explicitly adopted an ontology of this kind (though others within the outsourcing literature could be interpreted as implicitly doing so). Williams, Hay, and Macdonald (2011) depicted expertise as "connected to a broader politics ... that works to manufacture demand" (p. 410). For them, one can and should interrogate "what constitutes expertise in any given situation, what factors influence its constitution, whose interests are and are not served by these processes of constitution and 
their effects" (p. 410). Likewise, Williams and Macdonald (2015) conceptualised expertise "as a product of the practices that get labelled 'expert,' and the practices through which 'expert' practices get labelled as such” (p. 68). Thus, in the conceptualisations underpinned by this ontology, expertise and experts were taken to be attributions arising out of a field of agonistic social relations. Specifically, HPE teaching expertise was conceived of as constituted through relations of supply and demand, and the category of expert HPE teacher was conceived as a product of the ways in which social relations establish, maintain or challenge the boundaries defining those deemed expert and those who are not.

A network metaphor underpinned the third ontology. Two articles adopted this ontology. Powell (2015) conceptualised the expert and inexpert teacher as interconnected subject positions within an interlinked cluster of "organisations, discourses, rationalities, practices, regulations, individuals and moralities" (p. 75) assembled together in an effort to shape human conduct towards the ends of neoliberal government. Similarly, Enright et al. (2020) conceptualised expertise "as an awkward arrangement of multiple, tangled, contingent entities, perspectives and practices" (p. 207) connecting "people, institutional arrangements, resources, devices and so on” (p. 219). In these conceptualisations, expertise was neither an attribute of experts, nor an attribution resulting from competing claims for expert status. Instead, both concepts were conceived of as fluid, fragile, and relationally emergent.

One way we interrogated the relationality of conceptualisations within the sample was by studying the classifications and distinctions used to give meaning to the categories of experts and expertise. Twenty-four articles contrasted expert with one or more other levels of proficiency. The most common was the contrast between expert and novice, or some similar category, such as non-expert or student teacher $(n=18)$. The most sophisticated classification was used in four articles. It contrasted expert teachers with novice, advanced beginner, competent, and proficient teachers (e.g., Piéron \& Carreiro da Costa, 1996). Within the 
sample, teaching expertise was sometimes conceptualised vis-à-vis coaching expertise, and expert HPE teachers in relation to external providers, and/or generalist, non-specialist, or classroom teachers. The sharpness of these distinctions varied across the sample, though most authors considered blurry boundaries problematic, particularly when participants conceived of external providers as experts (e.g., Petrie, Penney, \& Fellows, 2014).

Another way we analysed the relationality of the conceptualisations was by examining the components of their underpinning ontologies. Within psychologically oriented conceptualisations, expertise was a product of an interplay between the expert teacher, the subject matter, and the teaching context. Most psychological conceptualisations presented students as part of "the context," but offered little sense of what else counted as context and how it shaped, or was shaped, by the expert teacher or teaching expertise. Among the socially oriented conceptualisations, experts and expertise were presented as products of the relations between people. In other words, it was only interactions between teachers, students, parents, principals, external providers, and so on that gave meaning to the concepts of the expert teacher and teaching expertise. Finally, those conceptualisations based on a network ontology depicted the interplay of a much broader and more diverse range of entities, each of which contributed to the constitution of the expert and/or expertise.

Examining each conceptualisation's interrelated components also provided insights into the materialities of experts and expertise. Overall, there was little specific or meaningful acknowledgement of anything other than flesh-and-blood humans and their interpersonal relations as being especially consequential. Non-human entities such as props, equipment, facilities, or planning documents were occasionally mentioned (e.g., Chen \& Cone, 2003), but seldom in ways that suggested they were integral to expert teachers' practices, or were influential in defining what counted as expert/expertise. The exceptions to this absence were the two network conceptualisations. Indeed, Enright et al. (2020) provided the clearest 
theorisation of the materiality of expertise, and the most substantial illustration of how a variety of physical and digital artefacts and resources could shape and be shaped by expertise.

Last, we analysed the attention given to practices within the sample. Overall, the sample addressed experts and expertise vis-à-vis two sets of teaching practices within and beyond the HPE curriculum. Four articles attended to experts and expertise in the context of planning, eighteen referred to experts and expertise in terms of delivery, and fifteen did so in relation to both. Overwhelmingly, movement-related teaching tasks, especially those related to sports, were the most commonly studied or discussed practice. Twenty-two articles used observational methods to study these expert- or expertise-related planning and/or delivery practices, though ethnographic observations were rare. The remainder of the empirical articles used document analyses, or collected retrospective accounts of those practices using interviews, focus groups, or questionnaires.

From a performative perspective, the concern with teaching practices within the sample was largely descriptive of experts and expertise "out there," prior to, and independent of authors' definitions and descriptions. There was little evidence of authors presenting their conceptualisations as entangled in the existence or character of experts or expertise. Certainly, some authors argued that conceptualisations of expert teachers and teaching expertise were consequential insofar as they had the potential to influence the direction of future research (e.g., O’Sullivan \& Doutis, 1994), the goals of teacher education (e.g., Ennis, 1994), or the legitimacy of the subject (e.g., Enright et al., 2020). However, with the exception of Williams and Macdonald's (2015) reference to the entanglement of researchers in the supply of and demand for outsourced HPE, there was no formal, reflexive acknowledgement that authors' conceptualising practices were performative in the sense of helping bring experts and expertise into existence. Instead, the default position was the 
assumption that "expertise in teaching exists" (Siedentop \& Eldar, 1989, p. 257) and that a central task of the researcher is to find and report on it.

\section{Discussion}

Our aim in this article has been to review conceptualisations of experts and expertise in the context of HPE teaching, and to examine the extent to which these conceptualisations have acknowledged the relationality, materiality, and performativity of either entity. One motivation for doing so was the prominence of concerns about the supply of, and demand for, expertise and experts in recent literature on outsourcing in HPE, and the state of the subject more broadly. The persuasiveness of material-semiotic explorations of experts and expertise in other fields (e.g., Eyal, 2013; Landström \& Whatmore, 2014) was a second motivation for conducting this research. And a third, related motivation was the material-semiotic conviction that if research practices are performative, educational researchers should reflect on the realities their research practices enact, the consequences of those enactments, and the kinds of realities they want to help bring into being (Gorur, 2015). In the final section of this article, we discuss our scoping review findings in relation to these motivations.

We are concerned by the frequency with which experts and expertise were simplistically conceived or self-evidently used in the sample. Such conceptualisations and uses have the potential to dilute scholarly understandings and depictions of the complexities of HPE teaching and of HPE teachers' work. Furthermore, simplistic conceptions and selfevident use may inhibit researchers from problematising either term and conceptualising them otherwise. We argue that researchers should use the terms expert and expertise judiciously. When expertise is simply synonymous with knowledge, important nuances of meaning can be lost, such as the role of judgement (Stigler \& Miller, 2018). And when expert status is valorised, diminished social worth is attributed to other levels of proficiency (e.g., the competent teacher), creating potentially problematic public and professional expectations 
about what counts as a "good" HPE teacher, a "quality" HPE experience, or a "worthwhile" career. Moreover, when their informants talk of experts and expertise, we suggest researchers explore exactly what they mean and why, rather than taking such talk at face value. Indeed, research done in the spirit of the optional sixth, consultative stage of the scoping review process (Arksey \& O’Malley, 2005), that investigates how teachers, students, and others conceptualise experts and expertise in the context of HPE teaching, represents one avenue for future research.

We also have reservations about the ambiguous role of the material world in the conceptualisations we analysed. While there is ample recognition of the sociality of pedagogic relations, and of teachers' work more broadly, there is little sensitivity to the materialities of either. Very few conceptualisations directed attention to: the contribution of physical or digital artefacts, devices, resources, or architectures to the performance of HPE teaching tasks; the definition of what it means to perform these tasks better, faster, and with greater certainty of outcome; or jurisdictional claims over the performance of such tasks. Yet knowledge "always takes material forms" (Law, 1992, p. 381), and pedagogic relations always involve work with, on, or through mediating materials (e.g., Sørensen, 2009). The psychological and social conceptualisations analysed here enacted a human-centric version of HPE teaching ill-attuned to the extra-somatic. By privileging "the human," such conceptualisations are poorly equipped to register enactments of HPE teaching where "the expert" is not a fleshy, co-present, person (e.g., Gard \& Enright, 2016), where "expertise" is materialised in physical or digital programs and resources (e.g., Enright et al., 2020), or where such programs and resources are integral to performing in an "expert" way.

The tendency to centre an individual as the unit of analysis is a further issue arising from our review. When the expert teacher is depicted as an orchestrater or virtuoso, a version of teaching is enacted that foregrounds the work of a heroic individual coordinating, 
controlling, managing, and mastering events from the middle of the action. Such a version poses at least three problems to researchers. First, it places considerable emphasis on the individual at the centre of the action for the success or failure of these coordinating, controlling, managing, and mastering efforts. Again, given the complexities of teaching and of teachers' work, we believe researchers should be careful about conceptualising experts and expertise in ways that create the impression that teachers should be able to adapt or adjust themselves or the world at will. Second, when the teacher (or external provider) is placed at the centre of the action, one could question what space exists for students to assume the expert role or be included in pedagogic decision-making on the grounds they possess relevant expertise. This issue, which directly concerns the problems of extension and legitimacy, is particularly relevant to teachers and researchers concerned with practicing and promoting more democratic and student-centred versions of HPE. And third, when conceptualisations centre on the individual teacher, it becomes difficult to register the kinds of networked expertise illustrated by Enright et al (2020) and advocated by Armour (2010). As Enright et al. (2020) suggest, this "rewired network of HPE expertise, which leaves no room for knowledge monopolies" (p. 220), may have profound consequences for the knowledge, skill, and judgment required of HPE teachers as they engage in, or contest (see Powell, 2015), the practices that constitute their work within and beyond the classroom.

Finally, we recommend researchers widen and heighten their attention to practices when studying experts and expertise in the context of HPE teaching. To recapitulate an earlier point, researchers should recognise that the objects of their scholarly attention are, in part, enacted through the knowledge practices they use to attend to them. A number of corollaries flow from this proposition. As our findings illustrate, conceptualisations of experts and expertise have tended to enact a somewhat narrow version of HPE teachers' work (i.e., HPE-teacher-as-planner-and-deliverer of movement-based learning experiences addressing 
the subject matter of sport). Yet, as the outsourcing literature demonstrates, there are increasing requirements for teachers to perform knowledge brokering and boundary spanning roles (e.g., Sperka, Enright, \& McCuaig, 2018) vis-à-vis a broader and more diverse range of knowledge (see Enright et al., 2020). We believe researchers need to conceptualise experts and expertise in ways that are capable of registering and depicting this breadth and diversity of knowledge, and this wider scope of role. Doing so may require researchers to move beyond, or modify, those frequently cited definitions noted above, developed as they were in and for intellectual and educational circumstances quite different to those in which we find ourselves thirty years later. From a material-semiotic perspective, we also believe researchers should place greater emphasis on the ethnographic study of the practices through which experts and expertise are enacted (i.e., of experts- and expertise-in-the-making, see Cambrosio et al., 1992), since it is only through such detailed work that the messy practices of relationality and materiality become visible (Law, 2009). Without wishing to diminish the valuable insights provided by interviews, focus groups, document analyses, or questionnaires, we argue more attention should be paid to what people do in the name of experts and expertise, not just in what they say they do. At the very least, we suggest researchers treat what people say they do as one set of practices alongside the many through which experts and expertise are enacted.

\section{Conclusion}

The concepts researchers use "should bring about a new way of seeing something and not simply fix a label to something we think we already know about” (Buchanan, 2017, p. 473). In this article, we analysed existing conceptualisations of experts and expertise in the context of HPE teaching, and advocated a material-semiotic approach as a means of building on, and going beyond, them. Like Enright et al. (2020) and Powell (2015), we believe network conceptualisations, particularly material-semiotic ones, provide new ways of seeing experts 
and expertise, and challenge much that we think we know about them. In so doing, material semiotics opens up fruitful avenues for future research on the role of experts and expertise in shaping the potentialities of HPE, and the profession(s) involved in their pursuit. At a time when claims to expert status are growing, demand for expertise is high, and the bases of expert claims seem evermore uncertain and contestable, such work would seem critical. We therefore hope this review prompts researchers to question taken-for-granted, superficial, or common-sense understandings of experts and expertise, and to become more attuned to the relationality, materiality, and performativity of these entities.

\section{References}

Abbott, A. (1988). The system of professions: An essay on the division of expert labour. Chicago, IL: The University of Chicago Press.

Arksey, H., \& O’Malley, L. (2005). Scoping studies: Towards a methodological framework. International Journal of Social Research Methodology, 8(1), 19-32.

Armour, K. M. (2010). The physical education profession and its professional responsibility ... or .. why ' 12 weeks paid holiday' will never be enough. Physical Education and Sport Pedagogy, 15(1), 1-13.

Barker, D., Quennerstedt, M., \& Annerstedt, C. (2015). Inter-student interactions and student learning in health and physical education: A post-Vygotskian analysis. Physical Education and Sport Pedagogy, 20(4), 409-426.

Buchanan, I. (2017). Assemblage theory, or, the future of an illusion. Delueze Studies, 11(3), 457-474.

Callon, M., Lascoumes, P., \& Barthe, Y. (2009). Acting in an uncertain world: An essay on technical democracy (G. Burchell, Trans.). Cambridge, MA: The MIT Press.

Cambrosio, A., Limoges, C., \& Hoffman, E. (1992). Expertise as a network: A case study of the controversies over the environmental release of genetically engineered organisms. In N. Stehr \& R. V. Ericson (Eds.), The culture and power of knowledge: Inquiries into contemporary societies (pp. 341-361). Berlin, Germany: Walter de Gruyter.

Chen, W., \& Cone, T. (2003). Links between children's use of critical thinking and an expert teacher's teaching in creative dance. Journal of Teaching in Physical Education, 22(2), 169-185.

Collins, H. M., \& Evans, R. (2002). The third wave of science studies: Studies of expertise and experience. Social Studies of Science, 32(2), 235-296.

Colquhoun, H. L., Levac, D., O’Brien, K. K., Straus, C., Tricco, A. C., Perrier, L., . . Moher, D. (2014). Scoping reviews: Time for clarity in definition, methods, and reporting. Journal of Clinical Epidemiology, 67(12), 1291-1294.

Dalmer, N. K. (2020). Unsettling knowledge synthesis methods using institutional ethnography: Reflections on the scoping review as a critical knowledge synthesis tool. Qualitative Health Research, 1-13. doi:10.1177/1049732320949167

Díaz-Cueto, M., Hernández-Álvarez, J. L., \& Castejón, F. J. (2010). Teaching Games for Understanding to in-service physical education teachers: Rewards and barriers 
regarding the changing model of teaching sport. Journal of Teaching in Physical Education, 29(4), 378-398.

Dodds, P. (1994). Cognitive and behavioral components of expertise in teaching physical education. Quest, 46(2), 153-163.

Ennis, C. D. (1994). Knowledge and beliefs underlying curricular expertise. Quest, 46(2), 164-175.

Enright, E., Kirk, D., \& Macdonald, D. (2020). Expertise, neoliberal governmentality and the outsourcing of health and physical education. Discourse: Studies in the Cultural Politics of Education, 41(2), 206-222.

Evans, J., \& Davies, B. (2015). Physical education, privatisation and social justice. Sport, Education and Society, 20(1), 1-9.

Eyal, G. (2013). For a sociology of expertise: The social origins of the autism epidemic. American Journal of Sociology, 118(4), 863-907.

Eyal, G. (2019). The crisis of expertise. Cambridge, United Kingdom: Polity Press.

Fetzer, J. H. (1991). Aspects of the theory of definition. In J. H. Fetzer, D. Shatz, \& G. N. Schlesinger (Eds.), Definitions and definability: Philosophical perspectives (pp. 317). Dordrecht, Netherlands: Springer.

Gard, M., \& Enright, E. (2016). Computer says no: An analysis of three digital food education resources. Asia-Pacific Journal of Health, Sport and Physical Education, 7(3), 205-218.

Gorur, R. (2015). Situated, relational and practice-oriented: The actor-network theory approach. In K. N. Gulson, M. Clarke, \& E. B. Petersen (Eds.), Education policy and contemporary theory: Implications for research (pp. 87-98). New York, NY: Routledge.

Grant, M. J., \& Booth, A. (2009). A typology of reviews: An analysis of 14 review types and associated methodologies. Health Information and Libraries Journal, 26(2), 91-108.

Hardman, K., Murphy, C., Routen, A., \& Tones, S. (2014). World-wide survey of school physical education: Final report 2013. Paris, France: United Nations Educational, Scientific and Cultural Organisation.

Huang, Y. (2017). Introduction: What is pragmatics? In Y. Huang (Ed.), The Oxford handbook of pragmatics (pp. 1-18). Oxford, United Kingdom: Oxford University Press.

Lakoff, G., \& Johnson, M. (1980). Metaphors we live by. Chicago, IL: The University of Chicago Press.

Landström, C., \& Whatmore, S. J. (2014). Virtually expert: Modes of environmental computer simulation modeling. Science in Context, 27(4), 579-603.

Latour, B., \& Woolgar, S. (1986). Laboratory life: The construction of scientific facts (2nd ed.). Princeton, NJ: Princeton University Press.

Law, J. (1992). Notes of the theory of the actor-network: Ordering, strategy, and heterogeneity. Systems Practice, 5(4), 379-393.

Law, J. (2009). Actor network theory and material semiotics. In B. Turner (Ed.), The new Blackwell companion to social theory (pp. 141-158). Malden, MA: Wiley-Blackwell.

Law, J. (2017). STS as method. In U. Felt, R. Fouché, C. A. Miller, \& L. Smith-Doerr (Eds.), The handbook of science and technology studies (4th ed., pp. 31-58). Cambridge, MA: The MIT Press.

Law, J., \& Mol, A. (2008). The actor-enacted: Cumbrian sheep in 2001. In C. Knappett \& L. Malafouris (Eds.), Material agency: Towards a non-anthropocentric approach (pp. 57-77). Boston, MA: Springer.

Levac, D., Colquhoun, H. L., \& O’Brien, K. K. (2010). Scoping studies: Advancing the methodology. Implementation Science, 5(59), 1-9. 
Macdonald, D., Johnson, R., \& Lingard, B. (2020). Globalisation, neoliberalisation, and network governance. Discourse: Studies in the Cultural Politics of Education, 41(2), 169-186.

Munn, Z., Peters, M. D. J., Stern, C., Tufanaru, C., McArthur, A., \& Aromataris, E. (2018). Systematic review or scoping review? Guidance for authors when choosing between a systematic or scoping review approach. BMC Medical Research Methodology, $18(143), 1-7$.

O'Sullivan, M., \& Doutis, P. (1994). Research on expertise: Guideposts for expertise and teacher education in physical education. Quest, 46(2), 176-185.

Petrie, K., Penney, D., \& Fellows, S. (2014). Health and physical education in Aotearoa New Zealand: An open market and open doors? Asia-Pacific Journal of Health, Sport and Physical Education, 5(1), 19-38.

Piéron, M., \& Carreiro da Costa, F. (1996). Seeking expert teachers in physical education and sport. European Journal of Physical Education, 1(1-2), 5-18.

Powell, D. (2015). Assembling the privatisation of physical education and the 'inexpert' teacher. Sport, Education and Society, 20(1), 73-88.

Rocha, R. F., \& Clemente, F. M. (2012). Expertise in sport and physical education: Review through essential factors. Journal of Physical Education and Sport, 12(4), 557-559.

Schempp, P. G., Manross, D., Tan, S. K. S., \& Fincher, M. D. (1998). Subject expertise and teachers' knowledge. Journal of Teaching in Physical Education, 17, 342-356.

Sharpe, T., \& Hawkins, A. (1992). Expert and novice elementary specialists: A comparative analysis. Journal of Teaching in Physical Education, 12(1), 55-75.

Siedentop, D., \& Eldar, E. (1989). Expertise, experience, and effectiveness. Journal of Teaching in Physical Education, 8, 254-260.

Sørensen, E. (2009). The materiality of learning. Cambridge, United Kingdom: Cambridge University Press.

Sperka, L., \& Enright, E. (2018). The outsourcing of health and physical education: A scoping review. European Physical Education Review, 24(3), 349-371.

Sperka, L., Enright, E., \& McCuaig, L. (2018). Brokering and bridging knowledge in health and physical education: A critical discourse analysis of one external provider's curriculum. Physical Education and Sport Pedagogy, 23(3), 328-343.

Stigler, J. W., \& Miller, K. F. (2018). Expertise and expert performance in teaching. In K. A. Ericsson, R. R. Hoffman, A. Kozbelt, \& A. M. Williams (Eds.), The Cambridge handbook of expertise and expert performance (pp. 431-452). Cambridge, United Kingdom: Cambridge University Press.

Williams, B., Hay, P., \& Macdonald, D. (2011). The outsourcing of health, sport and physical educational work: A state of play. Physical Education and Sport Pedagogy, 16(4), 399-415.

Williams, B., \& Macdonald, D. (2015). Explaining outsourcing in health, sport and physical education. Sport, Education and Society, 20(1), 57-72. 